\title{
IBM KELOMPOK NELAYAN DESA TATELI II KECAMATAN MANDOLANG KABUPATEN MINAHASA DALAM MENERAPKAN SISTEM RANTAI DINGIN GUNA MENINGKATKAN PEMASARAN DAN PENDAPATAN Victoria E.N. Manoppo ${ }^{1}$ \\ 1) Staff Pengajar Program Studi Agrobisnis Perikanan Fakultas Perikanan dan Ilmu Kelautan Universitas Sam Ratulangi, Manado. Koresponden email: victoria.nicoline@unsrat.ac.id
}

\begin{abstract}
Science and technology activities for the community aims to provide knowledge to them in finding solutions to problems. Tateli II is one of the villages in Tateli II Village, Mandolang Sub-district, Minahasa District, North Sulawesi Province. Tateli II village fishermen are often or often confused with the marketing of fishery products because of the low selling price; this is because of their low state of knowledge about postharvest handling so that income is always low. Fishermen should be taught how to handle post-harvest catch so that when sold will create a reasonable price and at least be in accordance with the results of the business. One effort to maintain the quality of fishery products of fisherman production since harvested to the hands of consumers, and fish in a fresh / wet condition is handling with cold chain system (cold chain system).

Training methods are based on adult learning methods (self-taught) and classically by providing theory and practice through lectures and group discussions (FGD: Focus Group Disscution). Implementation is made by providing theory as much as $25 \%$ and practice as much as $75 \%$ for 8 months.

First, approach the village government to obtain permits and discuss the timing of meetings for the implementation of the technology extension / demonstration that will be implemented in view of the importance of time-gathering arrangements in this case the fishermen group.

Extension and training activities can provide a view to the fisherman about the importance of post-arrest handling that is to maintain the quality of the fish in a cold state so it is not easily damaged or rotten. Counseling is given to the fishermen either individually or in groups. Conducted in groups in order that they can use this group in developing a capture fishery business can propose funding and / or equipment aid proposals through existing groups.

Based on the results of observation, counseling and training, the activities of IbM Fishermen Group of Tateli II Village of Mandolang Sub-District of Minahasa Regency: 1. Fisherman Group of Tateli II Village of Mandolang Sub-district, have conducted fishing activities and there is desire from them all to use system where fish must be kept cool or keep it at a low temperature. 2. The fishermen group of Desa Tateli II Mandolang sub-district is able to understand that by maintaining the temperature of the fish remains cool the selling price can be high and apada can eventually increase their income. 3. Individual awareness as well as group members on the importance of group roles, spontaneously they want to submit fund and equipment proposal to the Government of North Sulawesi Province. Changes in attitude towards such development can provide a guarantee of the sustainability of their business so that the future can change the state of the economy and their daily circumstances and their families in a better direction.
\end{abstract}

Keywords: ekstention, Female Workers

\begin{abstract}
Abstrak
Kegiatan Iptek bagi masyarakat ini bertujuan memberikan pengetahuan kepada mereka dalam menemukan pemecahan permasalahan. Tateli II merupakan salah satu desa yang berada di Desa Tateli II Kecamatan Mandolang Kabupaten Minahasa, Provinsi Sulawesi Utara. Nelayan desa Tateli II kerap kali atau sering bingung dengan pemasaran hasil perikanan karena harga jual yang selalu rendah; hal ini karena keadaan pengetahuan mereka yang rendah tentang penanganan pascapanen sehingga pendapatan selalu rendah. Nelayan harus diajarkan bagaimana cara menangani hasil tangkapan pascapanen supaya bila dijual akan menciptakan harga yang layak dan minimal bisa sesuai dengan hasil usaha. Salah satu usaha untuk menjaga mutu hasil perikanan produksi nelayan sejak dipanen sampai di tangan konsumen, dan ikan dalam keadaan segar/basah yaitu penanganan dengan system rantai dingin (cold chain system).

Metode pelatihan dilakukan berdasarkan metode pembelajaran orang dewasa (otodidak) dan secara klasikal dengan memberikan teori dan praktek melalui ceramah dan diskusi kelompok (FGD: Focus Group Disscution). Pelaksanaannya dibuat dengan cara memberikan teori sebanyak 25\% dan praktek sebanyak $75 \%$ selama 8 bulan. Pertama, melakukan pendekatan kepada pemerintah desa untuk mendapatkan ijin serta mendiskusikan tentang waktu pertemuan untuk pelaksanaan penyuluhan/demonstrasi teknologi yang akan diterapkan mengingat pentingnya pengaturan waktu mengumpulkan masa sekalipun dalam hal ini kelompok nelayan.

Kegiatan penyuluhan dan pelatihan dapat memberikan pandangan kepada nelayan akan pentingnya penanganan pasca penangkapan yaitu harus mempertahankan mutu ikan dalam keadaan dingin sehingga tidak mudah rusak atau busuk. Penyuluhan diberikan kepada nelayan baik secara individyu ataupun secara berkelompok. Dilakukan secara berkelompok agar disuatu saat mereka bisa menggunakan kelompok ini dalam mengembangkan usaha perikanan tangkap dapat mengusulkan proposal bantuan dana dan atau peralatan melalui kelompok yang ada.
\end{abstract}


Berdasarkan hasil pengamatan, penyuluhan dan pelatihan, maka kegiatan IbM Kelompok Nelayan Desa Tateli II Kecamatan Mandolang Kabupaten Minahasa : 1. Kelompok nelayan Desa Tateli II Kecamatan Mandolang, sudah melaksanakan kegiatan penangkapan ikan dan ada keinginan dari mereka semua untuk menggunakan sistem dimana ikan harus tetap dingin atau tetap pada suhu rendah. 2. Kelompok nelayan Desa Tateli II Kecamatan Mandolang mampu memahami bahwa dengan mempertahankan suhu ikan tetap dingin maka harga jual bisa tinggi dan apada akhirnya bisa meningkatkan pendapatan mereka. 3. Kesadaran secara individual dan juga anggota kelompok akan pentingnya peranan kelompok, secara spontanitas mereka ingin mengajukan proposal dana dan peralatan ke Pemerintah Provinsi Sulut. Perubahan sikap ke arah pengembangan demikian dapat memberikan jaminan keberlanjutan usaha mereka sehingga kedepannya bisa merubah keadaan perekonomian dan keadaan sehari-hari mereka dan keluarganya ke arah yang lebih baik.

Kata Kunci : extensions, training, cold chain

\section{PENDAHULUAN}

Masyarakat nelayan di kelurahan ini sangat rajin dan ulet sejak jaman dulu atau sejak jaman kakek atau orang tua mereka. Ini disebabkan karena mereka mendapatkan ketrampilan melaut dari orang tua mereka secara turun temurun. Namun, dengan berkembangnya teknologi dan bertambahnya jumlah nelayan dan tidak diikuti oleh perubahan alat tangkap/ masi tetap tradisional, tidak dikuti dengan pengembangan usaha atau pengembangan pengolahan produk dan pemasaran masih tradisional, sehingga menyebabkan keadaan mereka tetap seperti dulu dimana tidak ada perubahan-perubahan yang signifikan artinya masi tetap tradisional, pendapatan masih rendah dan kualitas hidup dibawa standar.

Cara pemaran hasil tangkapan masih berbelit-belit sehingga ikan sudah terlanjur busuk tapi belum sampai ke tangan konsumen. Di samping itu mreka masih menggunakan es batu dalam hal pemgwetan ikan hasil tangkapan, di mana cara ini sangat rentang dengan dengan proses pembusukan yang cepat.

Akibat dari semua itu, maka pendapatan mereka bisa menurun bahkan merugi usaha mereka yang pada akhirnya akan menurunkan tingkat kesejahteraan mereka. Untuk itu memang perlu diadakan penyuluhan, melalui pengabdian pada masyarakat untuk mengatasi dan mencari jalan keluar dari masalah-masalah mereka.
Masyarakat nelayan di sini sebenarnya bisa berproduksi atau produktif asalkan ada kepedulian dari pihak-pihak terkait.

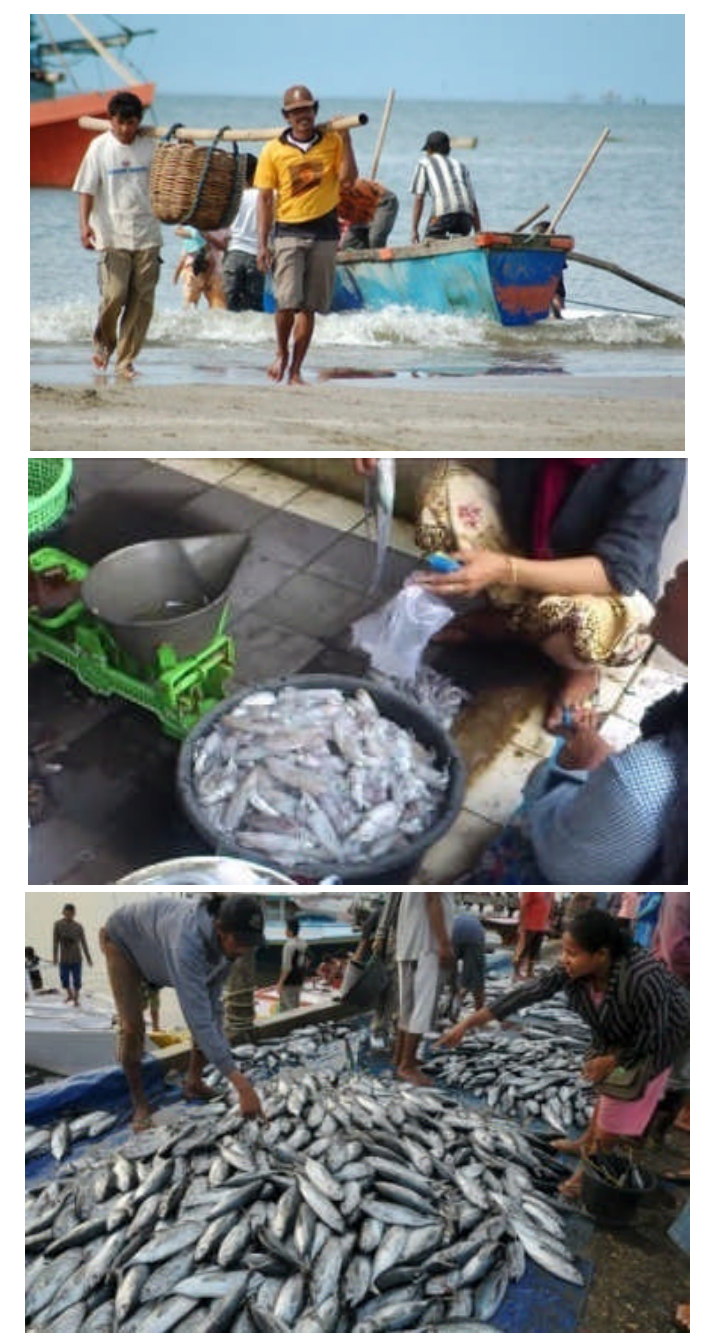

Gambar 1. Profil Mitra Usaha

Berdasarkan analisis situasi dan pengamatan di lapangan serta hasil diskusi kelompok bahwa masalah yang dihadapi mereka yaitu belum tahu cara bagaimana memasarkan ikan secara 
efektif dan efisien dan bermasalah juga dalam hal menangani ikan hasil tangkapan karena mereka belum atau bahkan tidak memiliki alat yang lebih modern untuk pengawetan ikan.

\section{METODOLOGI PENELITIAN}

Metode pelatihan dilakukan berdasarkan metode pembelajaran orang dewasa (otodidak) dan dilaksanakan secara klasikal dengan memberikan teori dan praktek melalui ceramah dan diskusi kelompok secara terarah $(F G D=$ Focus Group Discussion). Pelaksanaan teori diberikan sebanyak $25 \%$ dan praktek sebanyak $75 \%$, pelaksanaannya selama 8 (delapan) bulan. Bulan pertama persiapan kegiatan, bulan kedua pelaksanaan pelatihan 3 hari (8 jam/hari) pemantauan evaluasi monitoring dan pendampingan pada bulan berikutnya sampai selesai akan diadakan penerapan di lapangan.

Instruktur/penceramah adalah staf pengajar di Fakultas Perikanan dan IImu Kelautan yang mempunyai keahlian di bidang Sosial Ekonomi Perikanan. Peserta adalah anggota kelompok nelayan yang menjadi target dengan peran sertanya sebagai objek kegiatan.

Proses pelatihan menggunakan alat audio visual, proyektor/infokus, kertas plano, spidol, masing-masing peserta mendapatkan materi dalam bentuk makalah dan alat tulis menulis. Partisipasi mitra dalam kegiatan ini adalah usahanya akan dijadikan bahan praktek sebagai tindak lanjut dari kegiatan kelompok mitra diharapkan akan mempraktekkan sendiri di lapangan dan akan didampingi oleh Tim Pelaksana dan akan dilakukan pemantauan setiap bulan sampai kegiatan ini selesai. Metode pelaksanaan dilakukan dengan penyuluhan dan pelatihan kepada kelompok nelayan secara khusus dan masyarakat pada umumnya selanjutnya diskusi dengan monitoring dan evaluasi.

Proses kegiatan yang sudah dilakukan semuanya melibatkan kelompok mitra secara khusus dan masyarakat secara umum, agar supaya baik nelayan maupun masyarakat mengetahui akan proses kegiatan penerapan sistim rantai dingin. Hasil akhir juga kelompok ini akan menjadi model dalam pengembangan pada kelompok nelayan yang lain yang akan menjalar ke desa-desa sekitarnya.

\section{HASIL DAN PEMBAHASAN}

Pelaksanaan pengabdian kepada masyarakat dalam bentuk program penerapan IPTEKS telah dilaksanakan di Kelompok Nelayan Kecamatan Kabupaten Minahasa dilakukan melalui beberapa tahap perkunjungan:

Pertama, melakukan pendekatan kepada pemerintah desa untuk mendapatkan ijin serta mendiskusikan tentang waktu pertemuan untuk pelaksanaan penyuluhan/demonstrasi teknologi yang akan diterapkan mengingat pentingnya pengaturan waktu mengumpulkan masa sekalipun dalam hal ini kelompok nelayan. Tim mendapatkan respons yang positif dari pemerintah desa yang ternyata sangat terbuka untuk menerima kehadiran tim dan segera mengatur waktu pertemuan selanjutnya.

\section{Kegiatan Penyuluhan}

Kegiatan penyuluhan dilakukan setelah membuat perjanjian untuk pertemuan dan pelaksanaan penyuluhan. Penyuluhan dalam kegiatan ini dilakukan pada anggota kelompok nelayan Desa Tateli II Kecamatan Mandolang Kabupaten Minahasa. 
$\begin{array}{llr}\text { Materi } & \text { penyuluhan } & \text { berupa } \\ \text { peningkatan } & \text { kemampuan } & \text { dan }\end{array}$ keterampilan dalam pengelolaan usaha penangkapan ikan dengan menerapkan sistem rantai dingin yaitu ikan handaknya berada dalam keadaan dingin atau suhu rendah mulai dari tertangkapnya ikan sampai ke tangan akhir yaitu konsumen, dan peningkatan produksi, pemasaran dan penguatan modal sosial. Materi ini dipilih sesuai dengan kondisi masyarakat nelayan yang kurang melibatkan diri pada kelompok. Padahal dalam pendanaan untuk nelayan selalu disalurkan melalui kelompok nelayan.

Kelompok nelayan Desa Tateli II Kecamatan Mandolang sudah cukup lama melalukan kegiatan dalam kelompok, namun belum efektif karena ketidaktahuan nelayan akan pentingnya peningkatan kinerja kelompok. Melalui hasil penyuluhan banyak masyarakat nelayan bertanya-tanya implikasi, jika mereka terlibat dalam kelompok. Banyak nelayan ingin melakukan kerjasama guna mengefektifkan usaha penangkapan ikan dan penanganannya sehingga bisa terjual dengan harga tinggi dan bisa meningkatkan pendapatan mereka.

\section{Implikasi Kegiatan}

Kegiatan penyuluhan dan pelatihan dapat memberikan pandangan kepada nelayan akan pentingnya penanganan pasca penangkapan yaitu harus mempertahankan mutu ikan dalam keadaan dingin sehingga tidak mudah rusak atau busuk. Karena Makin berkurangnya mutu ikan maka harga jualpun ikut menrun sehingga pendapatan nelayan pasti menurun atau rendah/. Penyuluhan diberikan kepada nelayan baik secara individyu ataupun secara berkelompok. Dilakukan secara berkeklompok agar disuatu saat mereka bisa menggunakan kelompok ini dalam mengembangkan usaha perikanan tangkap dapat mengusulkan proposal bantuan dana dan atau peralatan melalui kelompok yang ada.

Keberadaan kelompok nelayan Malos 3 dengan karakteristik kelompok usaha perikanan tangkap pelagis, potensial pengembangannya. Hal ini disebabkan lokasi strategis kelompok nelayan yang tidak jauh dari pusat kota dan dekat dengan sumber dana dari Pemerintah Kabupaten Minahasa. Melalui Dinas Kabupaten Minahasa kelompok nelayan Desa Tateli II Kecamatan Mandolang dapat mengajukan proposal guna mendapatkan dana dan peralatan untuk kemajuan dan perkembangan kelompok menjadi lebih baik.

Keterbatasan dari solusi yang ditawarkan ialah keterbatasan pendidikan dasar nelayan. Kemampuan mencerna yang berbeda-beda menurut tingkat pendidikan, membuat Tim IbM harus menyamakan pengetahuan sehingga sebagian besar nelayan mampu menangkap dengan baik esensi dari pemahaman akan pentingkan kelompok nelayan sebagai modal sosial yang perlu ditumbuh kembangkan.

\section{KESIMPULAN DAN SARAN}

Berdasarkan hasil pengamatan, penyuluhan dan pelatihan, maka kegiatan IbM Kelompok Nelayan Desa Tateli II Kecamatan Mandolang Kabupaten Minahasa, dapat simpulkan :

1. Kelompok nelayan Desa Tateli II Kecamatan Mandolang, sudah melaksanakan kegiatan penangkapan ikan dan ada keinginan dari mereka semua untuk menggunakan sistem dimana ikan harus tetap dingin atau tetap pada suhu rendah. 
2. Kelompok nelayan Desa Tateli II Kecamatan Mandolang mampu memahami bahwa dengan mempertahankan suhu ikan tetap dingin maka harga jual bisa tinggi dan apada akhirnya bisa meningkatkan pendapatan mereka.

3. Kesadaran secara individual dan juga anggota kelompok akan pentingnya peranan kelompok, secara spontanitas mereka ingin mengajukan proposal dana dan peralatan ke Pemerintah Provinsi Sulut. Perubahan sikap ke arah pengembangan demikian dapat memberikan jaminan keberlanjutan usaha mereka sehingga kedepannya bisa merubah keadaan perekonomian dan keadaan sehari-hari mereka dan keluarganya ke arah yang lebih baik.

\section{Saran}

Disarankan untuk segera
mengajukan permohonan kepada
pemerintah untuk pengadaan sarana
penangkapan maupun sarana hasil
tangkapan.

\section{DAFTAR PUSTAKA}

Direktur Jenderal Pengolahan dan Pemasaran Hasil Perikanan, 2007. Masalah dan Kebijakan Peningkatan Produk Perikanan Untuk Pemenuhan Gizi Mayarkat. Disampaikan pada Seminar Nasional Hari Pangan Sedunia. Departemen Kelautan dan Perikanan.
Halim G., Raja O.S.G. dan Alam B. 2014. Pemilihan Sistem Rantai Dingin (Cold Chain) Daging Segar yang Memenuhi Persyaratan Halal. Departemen Komunikasi dan Pengembangan Masyarakat, Fakultas Ekologi Manusia, Institut Pertanian Bogor.

Hapsari, D.T. 2014. Distribusi dan Margin Pemasaran Hasil Tangkapan Ikan Tongkol (Euthinnus affinis) di TPI Ujingbatu Jepara. Jurnal Aquasains. Jurnal IImu Perikanan dan Sumberdaya Perairan. Vol. 2 No. 2.

Hardi Y., Alfian Z. dan Hasan B.N. 2013. Pola Pemasaran Ikan Laut Segar dan Faktor-Faktor Yang Mempengaruhi Konsumsi Ikan Masyarakat di Kecamatan Sijunjung Kabupaten Sijunjung Propinsi Sumatera Barat. Open Jurnal Systems. Vol 2. No. 2.

Masud, F. 2014. Strategi Pengembangan Pemasaran Ikan Sidat (Anguilla bicolor) di Unit Pengelola Perikanan Budidaya (UPPB) Desa Deket, Kecamatan Deket, Kabupaten Lamongan, Jawa Timur. Jurnal Eksakta Vol 2 No1 Maret 2014.

Oktariza, W. Achmad F., Istiqlaliyah M., Yatri I. K. Heri A. 1996. Studi Distribusi Pemasaran Basil Perikanan Laut dari Pelabuhan Ratu, Sukabumi, Jawa Barat. Buletin Ekonomi Perikanan No. 27. ISSN 0854-S804.

Peraturan Pemerintah Republik Indonesia Nomor 57 Tahun 2015. Tentang Sistem Jaminan Mutu dan Keamanan Hasil Perikanan serta Peningkatan Nilai Tambah Produk Hasil Perikanan.

Wiyono E.S. 2013. Kendala dan Strategi Operasi Penangkapan Ikan Alat Tangkap Bubu di Muara Angke, Jakarta. Jurnal Ilmu Perikanan Tropis Vol. 18. No. 2, April 2013 - ISSN 14022006.

Yuwono, B; Ransiska R.Z. dan Nurmala K.P., 2012. Faktor-Faktor yang Mempengaruhi Penerapan Cara Produksi yang Baik dan Standar Prosedur Operasi Sanitasi Pengolahan Fillet Ikan di Jawa. Jurnal IPB. Vol. 7 No. 1 ISSN 20858418. 
Available online :http://ejournal.unsrat.ac.id/index.php/akulturasi 